\title{
Perseverance and effectiveness of action: the effect of the fit between individual differences in willpower and the situational context
}

\author{
Romana Kadzikowska-Wrzosek \\ University of Social Sciences and Humanities, Faculty in Sopot, Sopot, Poland
}

\section{BACKGROUND}

Invoking the fit theory between a person and the environment, the author of which is Lawrence A. Pervin, an attempt to explain the influence exerted by willpower differences and the situational context on perseverance and action effectiveness is made.

\section{PARTICIPANTS AND PROCEDURE}

Two studies were conducted to test the effect of the situational context and willpower differences on perseverance and action effectiveness. The first study involved 120 participants ( 88 females and 32 males) between 17 and 19 years of age $(M=18.28 ; S D=0.56)$. The researched group in the second study included 230 participants $(160$ females and 70 males) between 20 and 53 years of age $(M=25.19$; $S D=5.04)$. In the first study perseverance and action effectiveness were assessed on the basis of the performance level and the amount of time spent on the computer task. In the study 2 to evaluate the effectiveness used subjective progress assessment in achieving individual goals. In both of these studies, evoked a sense of autonomy vs. induced a sense of external control and the measurement of will-power differences was conducted on the basis of Kuhl's ACS-90 questionnaire.

\section{RESULTS}

The results of study 1 confirm that perseverance and action effectiveness in the case of people with low willpower level (state-oriented) is greater in conditions creating a sense of pressure/external control. In the case of people with high willpower (action-oriented), the method of influencing by the situational context is not of major significance to their perseverance and effectiveness. The results of study 2 show that intention implementation in conditions creating a sense of external control increases progress assessment in achieving goals declared by the state-oriented. However, no positive influence of intention implementation on the assessments of progress made by action-oriented individuals was confirmed.

\section{CONCLUSIONS}

The cumulative results of the two presented studies confirm that the perseverance and action effectiveness of people with low willpower (state-oriented) are determined by the specific kind of fit between personal predispositions and the situational context. In turn, people with high willpower (action-oriented) act, to a larger extent, on the basis of internal regulatory mechanisms, somehow regardless of the way in which the situational context exerts an influence on them.

\section{KEY WORDS}

person-environment fit theory; perseverance; effectiveness; action vs. state orientation; autonomy; external control

CORRESPONDing Author - Romana Kadzikowska-Wrzosek, Szkoła Wyższa Psychologii Społecznej,

Wydział Zamiejscowy w Sopocie, e-mail: rkadzikowska-wrzosek@swps.edu.pl

AUthors' CONTRIBUtion - A: Study design - B: Data collection - C: Statistical analysis - D: Data interpretation ·

E: Manuscript preparation · F: Literature search · G: Funds collection

TO CITE THIS ARTICLE - Kadzikowska-Wrzosek, R. (2013). Perseverance and effectiveness of action: the effect of the fit between individual differences in willpower and the situational context. Current Issues in Personality Psychology, 1, 26-38. 


\section{BACKGROUND}

At the end of 1960s, the American personality psychologist Lawrence A. Pervin presented in one of his papers the Person-Environment Fit Theory (PE Fit Theory). In accordance with this model, the level of achievements, satisfaction and stress experienced by a person while exposed to stress is determined by the fit between their individual predispositions and the environmental conditions. Empirical support for this model comes from (quoted by the author) the results of many studies conducted in the field of educational and organizational psychology. They show that a good fit between individual predispositions and the environment results in high achievement level, low stress level and high satisfaction level in the case of a person executing a task. In turn, a poor fit is associated with low achievement level, high stress level and low satisfaction level (Pervin, 1968).

Currently, the model proposed by Pervin is applied in different domains of psychology. For instance, the recent research of Canadian psychologists confirms the assumptions behind this model as far as the field of organizational psychology is concerned. The authors of the research invoke the PE Fit Theory, trying to explain the relation between self-determination level (cf. Ryan \& Deci, 2000), work organization, experienced stress and fear level, and involvement in executing professional duties. The results of the conducted experiment have confirmed that in the case of people characterized by low self-determination, being unable to organize their work was a factor protecting them from stress. In turn, the possibility to decide about work organization on their own, in their case increased stress, and it significantly influenced their experienced fear level and intrinsic motivation. Conversely, in the case of people with high self-determination, the possibility to organize their own work made it easier to plan in an adaptive way. Generally, the research results showed that the possibility to organize work causes fear and de-motivates people with low self-determination, but people with high self-determination take advantage of the possibility to organize their own work with the use of strategic planning, which makes it possible to reduce adverse stress impact (Parker, Jimmieson \& Amiot, 2013).

The assumptions behind Pervin's fit model are also confirmed by studies during which psychologists strived to define perseverance and action effectiveness determinants. The results of their investigations in this field show that an important role is played in this case both by individual predispositions and the situational context alike. It seems that the certain kind of fit between the motivational influence of the situational context and individual differences in action control mechanisms effectiveness is particularly significant (Baumann \& Kuhl, 2005; Cervone et al., 2004; Cervone et al., 2011; Kadzikowska-Wrzosek, 2011a, 2011b, 2012).

\section{DETERMINANTS OF PERSEVERANCE AND ACTION EFFECTIVENESS}

In contemporary psychology it is assumed that goaldirected action is a people-specific behaviour. $\mathrm{Hu}$ man beings are agents and their actions are the uninterrupted process of moving towards (or away from) particular goals (Carver \& Scheier, 2011; KadzikowskaWrzosek, 2010; Mądrzycki, 1996). For psychologists, a particularly important notion is currently a goal as a specific cognitive motivation. A goal is viewed as the cognitive representation of a certain positive future state that a person strives to achieve, or a negative state a person tries to avoid. As Charles S. Carver and Michael F. Scheier emphasize (2011), the category of a goal is broad enough to include both long-term aspirations and short-term tendencies. The authors also point out that, for many personality psychologists, getting to know a person is the same as learning about their goals (Carver \& Scheier, 2011, p. 4). Psychologists are interested not only in goals as such, their properties and their organization, but also in the process of achieving these goals. After formulating a goal, regulating an action targeted at achieving it may include such processes as planning, adopting certain action strategies, progress assessment and maintaining or reviewing the direction of action thus far (Sansone \& Harackiewicz, 1996).

In psychological research into motivation and selfregulation processes, the fundamental issue seems to be finding an answer to the question of factors determining success in achieving goals (Gollwitzer, Fujita \& Oettingen, 2004; Mądrzycki, 1996; Vohs \& Schmeichel, 2007). Frequently, motivation theories are concentrated solely on the factors which decide about starting an action (Łukaszewski \& Marszał-Wisniewska, 2006), while both psychological research and day-to-day observations confirm that starting an action does not yet determine whether a goal will be achieved. Very often it even turns out that achieving a goal is preceded by multiple attempts, and often an initiated action ends before achieving a goal (Polivy \& Herman, 2000). For instance, research has shown that people formulating so-called 'New Year's resolutions' admit that they have started, on average, actions attempting to achieve a goal approximately five times and that among those who do not fulfil these resolutions, approximately $60 \%$ make renewed attempts the following year (Prochaska, DiClemente \& Norcross, 1992). These results confirm that different factors are likely to influence the decision about starting an action and about continuing it. In light of the results of this type of research, a particular importance is acquired by the question of the person- 
ality and the situational determinants of persevering and effective completion of undertaken tasks.

Most often, difficulties in starting an action result from the fact that people either cannot overcome their initial reluctance to act, or do not notice the circumstances conducive to starting actions to achieve their goals. In turn, a general lack of perseverance is the consequence of giving up an action when facing difficulties, obstacles and, sometimes, initial failures. Peter M. Gollwitzer et al. assume that difficulties in achieving goals consistently result from the inability to overcome the disruptive influence of both external factors (e.g. temptations and competitive goals) and internal factors (e.g. anxiety, reaching the limits of ability to self-regulate) (Gollwitzer et al., 2004; Wieber \& Gollwitzer, 2010)

Alexander J. Rothman (Rothman, 2000; Rothman, Baldwin \& Hertel, 2004), in turn, assumes that people take actions to achieve a goal because of a positive imagination-stimulating vision of a goal or result already achieved. For instance, starting a diet is caused by the positive vision of oneself as slim and attractive. The influence of so-called 'possible selves' on actions is similarly viewed by Hazel R. Markus (Markus \& Ruvalo, 1989). However, according to Rothman, the ability to act perseveringly depends on whether during this action a person notices progress in achieving a goal. Of major significance is satisfaction with progress, which, to a considerable degree, is determined by whether an adopted goal is realistic. Very often, unrealistic goals result in people's failure to notice satisfying progress, and dissatisfying progress, according to Rothman, makes one likely to give up an action.

Carol Sansone and Judith M. Harackiewicz (1996), in turn, point out the need to differentiate between two kinds of causes, which, on the one hand are of major significance for starting an action, and on the other hand, for persevering with it. They suggest that an intentional activity is driven both by outcomederived motivation and process-derived motivation. A particularly important role of this kind of differentiation is seen in the case of achieving complex, long-term goals, in the case of which exceptional significance for perseverance is in the way of experiencing the action itself. In the case of this kind of tendency, when the reward (success related to achieving a goal) is postponed, the positive vision of success determines the starting action, but it is not enough to persevere facing adverse circumstances. Although an action is the source of rewarding experiences: satisfaction, pride and interest, even when achieving a goal, requires a long period of involvement or an exceptional mobilization because of obstacles and difficulties, a person will be able to persevere. Sansone and Harackiewicz claim, therefore, that taking action is determined in accordance with the 'expectation $x$ value' model, the outcome value and the probability of achieving it (outcome-derived motivation), while continuing an action by the ability to become positively involved (process-derived motivation). They assume as well that the action itself becomes the source of positive experiences when it matches the needs and preferences of a given person. Therefore, for example Sansone and Harackiewicz's research results show that executing tasks requiring competition and offering the opportunities of testing one's abilities is the source of positive experiences for people with high motivation achievements, but simultaneously does not offer such positive feelings for a person with low motivation achievement (Sansone \& Harackiewicz, 1996; Sansone, Wiebe \& Morgan, 1999).

The Sansone and Harackiewicz (1996) model suggests that the more reasons for achieving a goal are in accordance with the person's internal needs and preferences, the greater the ability to persevere in an action is. A similar standing is part of the self-determination theory of Richard M. Ryan and Edward L. Deci $(2000,2006,2008)$. In their opinion, the lack of action effectiveness and perseverance often results not so much from the power of motivation, as from the level of the autonomy of this motivation. If the situational context is conducive to shaping a positive and autonomous involvement, then the person's actions will be characterized by high effectiveness, perseverance and, additionally, creativity. In turn, exerting pressure or evoking the sense of external control will result in lower effectiveness, perseverance and lack of the sense of responsibility for achieved results.

Sansone and Harackiewicz's model shows as well that the more an action matches a person's internal needs and preferences, the greater their personal ability to regulate negative feelings experienced during an action, such as boredom, or the ability to evoke positive feelings, such as interest. Julius Kuhl, in his concept of personal action control mechanisms, draws attention to the connection between willpower and effect regulation, and confirms, on the basis of the results of many studies, that the foundation of the ability to persevere is the capacity to evoke a positive effect and to neutralize the negative effect (Koole, 2009; Koole \& Kuhl, 2007; Kuhl, 1996; Kuhl \& Kazén, 1999; Kuhl, Kazén \& Koole, 2006).

Kuhl's concept of 'willpower' (Baumann \& Kuhl, 2005; Kuhl, 1996; Kuhl et al. 2006) and the self-determination theory of Ryan and Deci (2000) to a certain degree are fitting when they see the causes of perseverance and effectiveness in the accordance of actions, internal needs and the system of values. People with strong will (action-oriented) and higher perseverance and effectiveness are simultaneously characterized by a better fit of achieved goals and internal preferences and needs, and a greater sense of self-determination (Baumann, Kaschel \& Kuhl, 2005; Kazén, Baumann \& Kuhl 2003; Kuhl \& Kazén, 1994). Simultaneously, the self-determination theory draws attention to the solely positive influence of the situa- 
tional context evoking a sense of autonomy on perseverance. In turn, the research conducted on the basis of Kuhl's concept proves that the lower the internal self-regulatory mechanisms efficiency is, the more perseverance and effective action is seen solely under conditions of pressure and coercion (Baumann \& Kuhl, 2005; Fuhrmann \& Kuhl, 1998). Therefore, what should be expected is the interactive influence of the situational context evoking the sense of external control versus the sense of autonomy and willpower differences. People with low willpower (state-oriented) will be more persevering and effective in the context of creating pressure than in creating a sense of autonomy. In turn, perseverance and effectiveness of those with high willpower (action-oriented) are more dependent on their internal self-regulatory mechanisms and, for that reason, are not subjected to the varied influences of the situational context.

\section{PRESENT STUDIES}

Two studies, both of which tested hypotheses concerning the connection between perseverance and action effectiveness and the situational context, in various ways motivating to take action (by evoking the sense of autonomy versus that of external control) and willpower differences, will be presented.

In the first study, the conditions supporting the sense of autonomy, or threatening it, were provided, and then it was investigated whether there was an interaction between the situational context and willpower differences in terms of determining differences in perseverance and action effectiveness.

In the second study, the influence of manual inclination to implement an intention and willpower differences on subjective progress assessment in achieving goals was analysed. Introducing a manual inclination to implement an intention was preceded by manipulation aiming at evoking the sense of autonomy versus the sense of external control.

In both of these studies the measurement of willpower differences was conducted on the basis of Kuhl's ACS-90 questionnaire (Polish adaptation: Marszal-Wiśniewska, 2002).

\section{STUDY 1}

The goal of this study was the verification of the following hypothesis:

Hypothesis: The influence of the situational context evoking the sense of autonomy versus creating pressure on perseverance and action effectiveness depends on individual differences in action effectiveness control mechanisms. State-oriented people achieve higher effectiveness and perseverance indicators in the context of creating a sense of external control than in the context of evoking a sense of autonomy. The situational context exerts a smaller influence on state-oriented action effectiveness and perseverance.

\section{Participants and procedure}

\section{Participants}

The researched group included 120 participants (88 females and 32 males) between 17 and 19 years of age $(M=18.28 ; S D=0.56)$. All the respondents were students of a Gdańsk secondary school. The respondents were randomly assigned to one of two groups: one in which a sense of pressure (external control) on executing a task was created (the external control group, $N=60 ; 48$ females and 12 males) and one in which a sense of positive involvement (autonomy support) on executing the task was created (the autonomy support group, $N=60 ; 40$ females, 20 males).

\section{Procedure}

At the beginning of the study all the participants answered questions with the use of the scale AOD/ SOD (decision-related action versus state orientation) of the ACS-90 Kuhl Questionnaire (Polish adaptation: Marszał-Wiśniewska, 2002). Later on, depending on the group, the respondents acquainted themselves with a manual aiming at creating the sense of pressure (external control) or, alternatively, of positive involvement (autonomy support). In the external control group the manual created pressure (control) by showing a potentially important role of the respondents for the success of the research and emphasizing their responsibility for a possible failure. Additionally, it was emphasized that the results of the research participant would be compared with those of other participants, and that they would constitute valuable feedback on their ability to concentrate their attention, which is of essential significance for solving intellectual problems effectively. In the text, such expressions as 'you should' and 'you must try hard' appeared.

In the autonomy support group a manual was used that supported the respondents' positive involvement by drawing attention to their feelings and emphasizing that their help, if they were able to execute the task, would provide valuable information. The manual contained the following expressions: 'please, try' and 'we believe that you will succeed'.

The research was conducted on small groups, and after making themselves acquainted with the manual, unlike for the experimental group, the respondents were presented with the principles of executing a task 'SYZYF' on a computer (Eukaszewski \& Marszał-Wiśniewska, 2006).

\section{Measured variables}

An independent variable in the research was individual differences in the scope of state-orientation ver- 
sus action-orientation. The basis for the assessment of differences in this scope, similarly to previous studies, was Kuhl's Action Control Scale (ACS-90) in the Polish adaptation by Marszal-Wiśniewska (2002). In the research, the AOD/SOD (decision-related action versus state-orientation) scale was used. This scale, according to Kuhl, is of major significance for persevering action. The computer task used in this research required dealing with the lack of a positive affect - monotony and boredom, and for that reason in the research the AOD/SOD scale, measuring individual differences in the scope of ability to evoke a positive affect, was used. The AOD/SOD scale in the researched sample obtained a satisfying reliability: Cronbach's $\alpha$ amounted to 0.79 .

In the research, a dependent variable was perseverance and task execution effectiveness. The basis for perseverance and effectiveness assessment was the results obtained by the respondents while executing a task 'SYZYF' on a computer. The task was developed by Główka and Buczny (Łukaszewski \& Marszał-Wiśniewska, 2006). This task consisted of maintaining the position of a computer mouse cursor on a small square moving on the confined space of a computer monitor. All respondents received the same manual, which informed them that: 'It is your task to maintain the position of a computer mouse cursor situated on the monitor screen with the use of a mouse, making sure that the cursor remains on a blue square. The blue square changes direction several times. This figure will be moving on a field delineated by the blue frame. Please, concentrate your attention on executing the task and maintain the position of the mouse cursor on the moving square as closely and as long as you can possible manage. If you decide that you cannot keep executing the task any longer, press the DELETE key on the keyboard'.

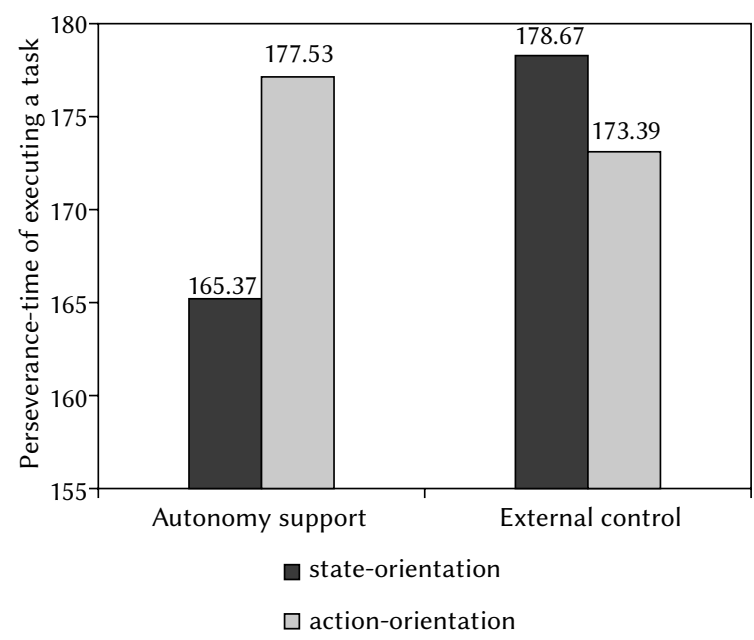

Figure 1. Task execution time for state-oriented versus the action-oriented people in the autonomy support and external control groups.
The following perseverance and effectiveness indicators were adopted - the dependent variable ( $\mathrm{Eu}-$ kaszewski \& Marszał-Wiśniewska, 2006):

- perseverance - task execution time in seconds;

- effectiveness - the level of executing the task (percentage of time for which the cursor was situated on the followed square);

- effective perseverance - a synthetic indicator taking into consideration task execution time and the level of execution. It was calculated by multiplying (the highest range assigned to the best result) unprocessed results concerning perseverance and effectiveness classified by ranges.

\section{Results and Discussion}

On the basis of the sum of results on the AOD/SOD scale (lower and higher than median: $M e=7$ ), the state-oriented people were differentiated from the action-oriented people, assuming that a person who obtained a result higher than the median was actionoriented while those who obtained a result lower than the median were state-oriented. Later on an Instruction (autonomy support versus external control) X Personality (state versus action-orientation) analysis of variance (ANOVA) was computed. The conducted analyses showed a significant interaction effect in the case of perseverance measured on the basis of task execution time, $F(1,116)=6.03 ; p<0.05$; $\eta^{2}=0.049$. The simple effect tests showed significant differences $(p<0.05)$ between the state-oriented and the action-oriented people in task execution time in the autonomy support group. In this group, the state-oriented people executed the task less perseveringly $(M=165.37 ; S D=31.20)$ than the action-oriented people $(M=177.53 ; S D=12.73)$. Simultaneously, it was recorded that there were significant differences $(p<0.01)$ in task execution time for state-oriented people in the autonomy support and external control groups. In the external control group, state-oriented people executed the task for a significantly longer time $(M=178.67 ; S D=11.04)$ than in the autonomy support group $(M=165.37 ; S D=31.20)$. No significant differences in task execution time between the action-oriented people in particular groups were established. The action-oriented people executed the task with equal perseverance in the case of the external control group $(M=173.39 ; S D=19.55)$ and the autonomy support group $(M=177.53 ; S D=12.73)$. The discussed results are presented in Figure 1.

The analysis of differences in the scope of task solving effectiveness also confirmed a significant interaction effect, $F(1.116)=7.58 ; p<0.05 ; \eta^{2}=0.061$. The simple effect tests revealed significant differences $(p<0.01)$ between the state-oriented and the action-oriented people in the autonomy support group. In this group, state-oriented people were less effective in solving a task $(M=28.11 ; S D=13.10)$ than 
were action-oriented $(M=37.24 ; S D=16.97)$. Simultaneously, it was confirmed that there were significant differences $(p<0.01)$ in task solving effectiveness by the state-oriented people in the autonomy support group $(M=28.11 ; S D=13.10)$ and the external control group $(M=37.61 ; S D=14.54)$. Such significant differences were not established in the case of the action-oriented people who were characterized by similar effectiveness in the autonomy support group $(M=32.12 ; S D=12.47)$ and in the external control group $(M=37.24 ; S D=16.97)$. The discussed results are presented in Figure 2.

In the case of an effective perseverance synthetic indicator, the analyses also showed a significant interaction effect: $F(1.116)=10.60 ; p<0.01 ; \eta^{2}=0.084$. The simple effect tests again confirmed significant differences $(p<0.05)$ between the state-oriented and the action-oriented people in the autonomy support group. In this group, state-oriented people in the scope of this synthetic indicator, measuring both perseverance and effectiveness alike, obtained lower values $(M=2518.14$; $S D=2237.85)$ than did the action-oriented people $(M=4391.35 ; S D=2878.95)$. Simultaneously, it was confirmed that there were significant differences $(p<0.01)$ in the effective perseverance of the state-oriented people in the autonomy support and external control groups. State-oriented people obtained a higher effective perseverance indicator in the external control group $(M=4549.59$; $S D=2542.27)$ than in the autonomy support group $(M=2518.14 ; S D=2237.85)$. No significant differences in the effective perseverance of the action-oriented people in the autonomy support group $(M=4391.35$; $S D=2878.95)$ and in the external control group $(M=3300.29 ; S D=2478.86)$ were shown. The discussed results are presented in Figure 3.

The state-oriented people, in comparison with the action-oriented people, showed less perseverance while executing a task in the group in which the sense of autonomy was evoked. Also, differences in action effectiveness (including effective perseverance) between the state-oriented and the action-oriented subjects were revealed solely in the autonomy support group. Generally, state-oriented people showed more perseverance and effectiveness in the external control group than in the autonomy support group. Such significant differences in perseverance and effectiveness in particular groups were not established in the case of the action-oriented people. Thereby, one may arrive at the conclusion that the assumptions formulated in the hypothesis were confirmed by the results of the conducted research.

In accordance with the research results of Kuhl et al., state-oriented people showed higher action effectiveness under conditions of external control/ pressure than under those of autonomy support (Baumann \& Kuhl, 2005; Fuhrmann \& Kuhl, 1998). The conditions of external pressure and informa-

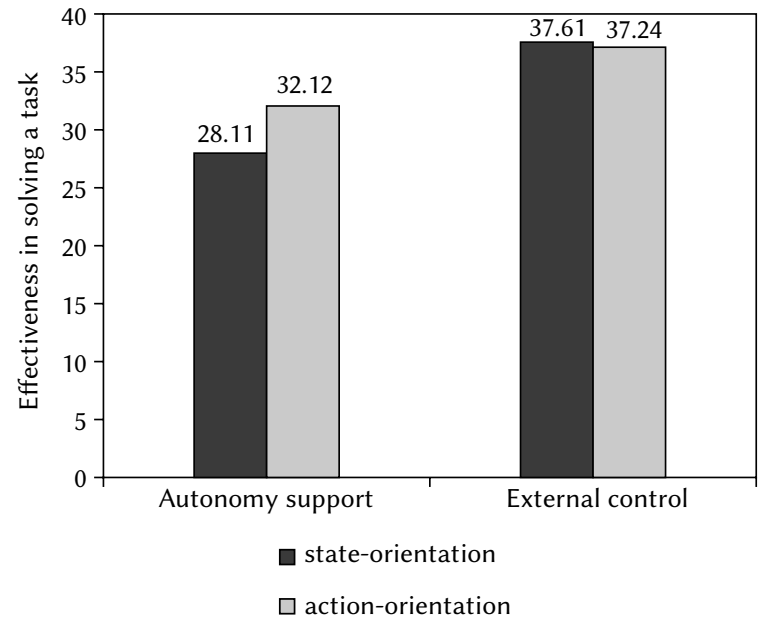

Figure 2. Effectiveness in solving a task by stateoriented and action-oriented people in the autonomy support and external control groups.

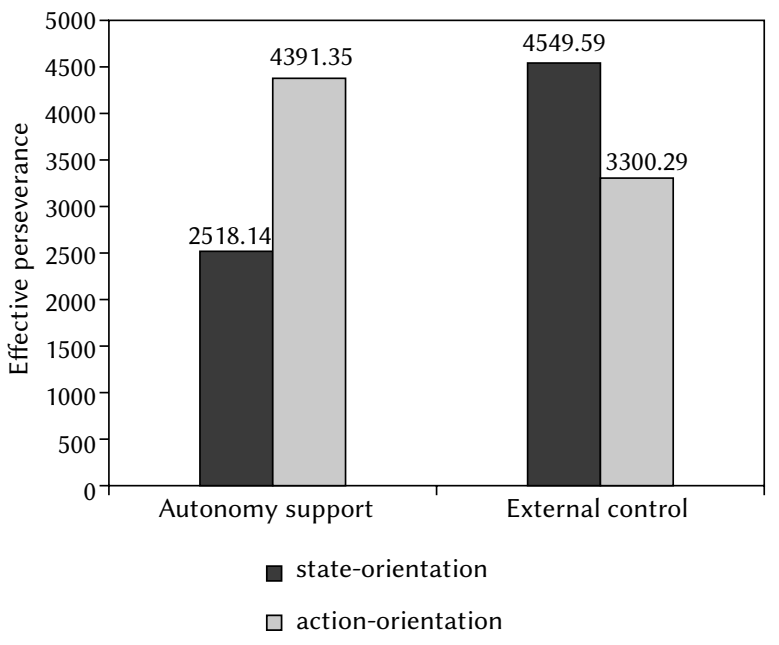

Figure 3. Effective perseverance of state-oriented and action-oriented people in the autonomy support and external control groups.

tion about the assessment of the executed task made state-oriented people more persevering and effective in executing the task in comparison with the situation when, supporting the sense of autonomy, an attempt was made to motivate them positively to execute the task. Differences between the state-oriented and the action-oriented people in perseverance and effectiveness were revealed solely in the context of supporting the sense of autonomy. It is possible to arrive at the conclusion that, contrary to the assumption of the authors of the self-determination theory, this type of context does not positively influence the action effectiveness of state-oriented people. The lack of significant differences in perseverance and action effectiveness of the action-oriented people in the context of creating a sense of external control 
and evoking the sense of autonomy confirms that these people act to a larger extent on the basis of internal regulatory mechanisms.

\section{STUDY 2}

The goal of the second study was to check whether the influence of implementation intention on the state-oriented people and the action-oriented people depends on the motivating method aiming to ensure implementation. On the basis of the results of the first study and theoretical assumptions, as well as research conducted in the field of self-determination theory (cf. also Baumann \& Kuhl, 2005; Kadzikowska-Wrzosek, 2011a, 2011b; Koestner et al., 2006), the following hypothesis was formulated.

Hypothesis: The influence of implementation intention on subjective progress assessment in achieving individual goals conducted by state-oriented and action-oriented people depends on the way of influencing the context motivating to implement the intention. The greatest influence on progress assessment conducted by state-oriented people is exerted by introducing implementation intention in the context of creating a sense of pressure and external control. Subjective progress assessment in achieving individual goals conducted by action-oriented people increases in the context of motivating to implement an intention in a way strengthening the sense of autonomy.

\section{Participants and procedure}

\section{Participants}

The researched group included 230 participants (160 females and 70 males) between 20 and 53 years of age $(M=25.19 ; S D=5.04)$. All the respondents were students of pedagogical and economic majors of three Gdańsk higher education institutions. The respondents were randomly assigned to one of three groups: a group in which they implemented an intention in a way simultaneously strengthening the sense of autonomy (implementation - autonomy support) ( $N=83$; 57 females, 26 males); a group in which they implemented an intention in a way creating a sense of control (implementation - external control) $(N=76$; 54 females, 22 males) and a group in which it was solely the respondents that enumerated individual goals and did not implement an intention (no implementation) ( $N=71 ; 49$ females, 22 males).

$\begin{array}{cccccccccc}0 & 1 & 2 & 3 & 4 & 5 & 6 & 7 & 8 & 9 \\ 0-9 \% & 10-19 \% & 20-29 \% & 30-39 \% & 40-49 \% & 50-59 \% & 60-69 \% & 70-79 \% & 80-89 \% & 90-100 \%\end{array}$

\section{Procedure}

The research included two stages. The participants were informed about that fact, and they were requested to write down the code (their parents' initials and date of birth) on all the questionnaires used in the research. At the first stage, all the people participating in the research filled in Kuhl's questionnaire (ACS90) in the Polish adaptation by Marszał-Wiśniewska (2002), and then they were requested to formulate, in accordance with the provided manual, three currently personally important goals ['individual projects' (Little, 1993; Little, Lecci \& Watkinson, 1992)]. Later on, depending on the group, the respondents implemented or did not implement an intention. In one of the groups, in which the respondents implemented an intention, the presentation of a manual explaining what intention implementation consisted of was preceded by manipulation aimed at creating a sense of pressure for implementation intention, and in the second of the groups by manipulation, aiming at evoking a sense of autonomy and positive support for intention implementation. The manuals used for introducing the sense of external control and autonomy support were developed on the basis of a manual from the research of Koestner et al. (2006) into intention implementation influence on the effectiveness of fulfilling 'New Year's Resolutions'. Later on, the respondents in both of the groups in which they implemented an intention acquainted themselves with the manual indicating the way in which they should act (how to formulate a plan). The respondents in all three groups placed questionnaires, filled in by themselves, in envelopes on which they wrote the code placed on the questionnaires themselves one more time. After one month, all the respondents assessed their progress in the scope of achieving goals on the basis of the scale they were provided with.

\section{Measured variables}

The independent variable in the research was individual differences in the scope of state-orientation versus action-orientation. The basis for the assessment of differences in this scope, similarly to study 1, was Kuhl's Action Control Scale (ACS-90) in the Polish adaptation by Marszał-Wiśniewska (2002). The AOD/ SOD scale in the researched sample obtained a satisfying reliability: Cronbach's $\alpha$ amounted to 0.73 .

A dependent variable in the research was subjective progress assessment in achieving goals. After a month, the respondents assessed progress in achieving goals, in accordance with the provided manual:

Figure 4. 
Assess, using the scale, the degree to which in the last three months you have made progress in achieving a goal that has been set. Look at the 'per cent ranges' placed below the scale, and estimate which of them most accurately describes the progress made by you in the last three months (see Figure 4).

As a progress indicator, the summed-up, and, next, averaged assessments concerning progress in the scope of the three chosen goals, are used.

Similarly to the course of the analysis of the results of study 1 and on the basis of the sum of results on the AOD/SOD (decision-related action versus state orientation) (lower/higher than the median; $M e=7$ ) scale, the state-oriented versus the action-oriented people were differentiated, assuming that people who obtained a result higher than the median were action-oriented, while those who obtained a result lower than the median were state-oriented. In order to test the hypothesis claiming that the different influence of intention implementation depends on the context motivating to implement an intention (operationalization: two methods of motivating to implement) on subjective progress assessment in achieving goals, two one-factor analyses of the ANOVA variations in the plan for independent groups, separately for the state-oriented and the action-oriented, were conducted. As a result of these analyses, in the case of the state-oriented people, a statistically significant effect of the changing membership of a group was obtained (implementation in the conditions of external control, implementation in the conditions of autonomy support and the lack of implementation), $F(2.139)=3.52 ; p<0.05$. The comparisons conducted post hoc with the use of Bonferroni test revealed significant differences $(p<0.05)$ between the implementation group in the conditions of external control and the lack of implementation. The state-oriented people in the no-implementation group assessed their progress in achieving goals as significantly lower $(M=4.18$; $S D=1.34)$ than those in the implementation group in the conditions of external control $(M=5.32 ; S D=2.16)$. Simultaneously, the assessments of progress conducted by the state-oriented people in the implementation group in the conditions of autonomy support did not differ significantly from assessments in the remaining groups $(M=4.77 ; S D=2.13)$.

In the case of the action-oriented people, the analysis did not show any significant influence of the membership of a group on progress assessment in achieving goals $F(2.85)=0.50$. The respondents in the no-implementation group assessed their progress similarly to the way in which the respondents in groups in which intention implementation was conducted under conditions of strengthening the sense of control and supporting the sense of autonomy did.

Simultaneously, the analysis confirmed significant differences between the state-oriented and the action-oriented people in the group in which the respondents implemented an intention under conditions supporting the sense of autonomy. In this group, the action-oriented assessed progress in achieving goals was significantly higher $(M=5.73 ; S D=2.02)$ than among the state-oriented people $(M=4.77$; $S D=2.13), t(79)=2.08 ; p<0.05$. Significant differences between the state-oriented and the action-oriented people were recorded in the no-implementation group as well. In the group in which the respondents solely enumerated goals and did not implement an intention, the action-oriented people assessed their progress in achieving goals significantly higher $(M=5.23$; $S D=2.31)$ than did the state-oriented people $(M=4.18$; $S D=1.74), t(69)=2.17 ; p<0.05$. The visualization of the discussed results is presented in Figure 5.

The results of study 2 partly confirmed the hypothesis which assumed, among others, that the influence of intention implementation on subjective progress assessment conducted by state-oriented versus action-oriented people depends on the method of motivation for implementing. The analysis of the results of study 2 showed significant differences in subjective progress assessment conducted by the state-oriented people in the implementation (the external control group) and no-implementation group. It transpired that the state-oriented people assessed their progress in achieving goals after introducing the manipulation creating the sense of pressure on intention implementation as higher. Simultaneously, the manipulation which was aimed at creating a sense of arbitrariness

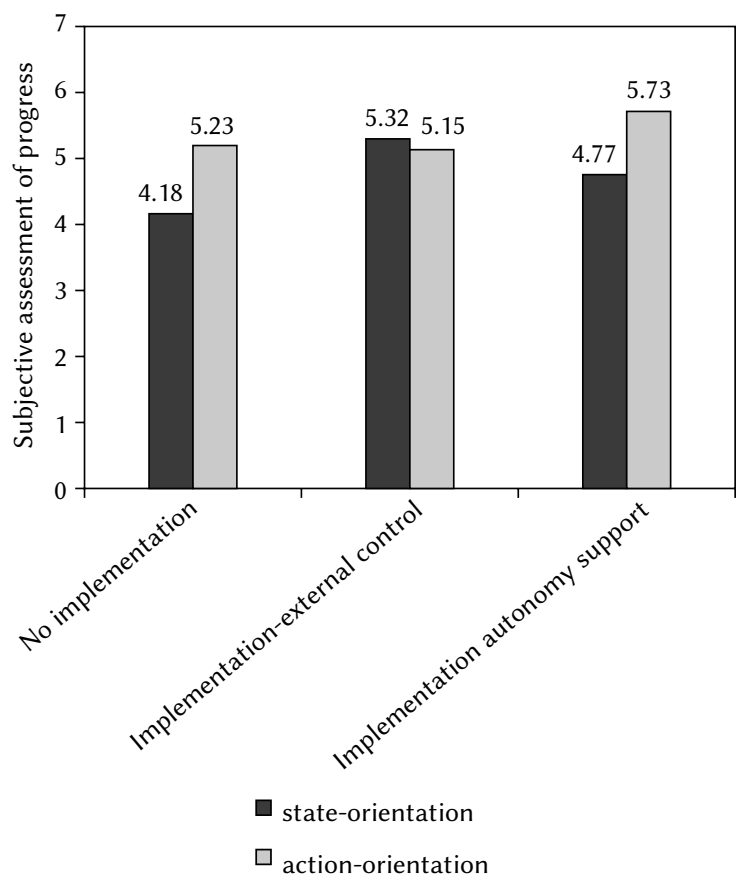

Figure 5. Subjective assessment of progress in achieving goals by state-oriented and action-oriented people in the no-implementation, implementation-external control and implementation-autonomy support groups. 
and motivated autonomously to implement an intention failed to bring, in the case of the state-oriented subjects, an equally positive result. Also, significant differences between the state-oriented and the actionoriented people in subjective success assessment in achieving goals in the no-implementation and the implementation-autonomy support groups were revealed. Thus it may be concluded that it is solely such a method of motivating to implement an intention which creates the sense of pressure and external control that eliminates the differences in action effectiveness generally occurring between the state-oriented and the action-oriented people. The results of study 2 did not show a beneficial influence of intention implementation on the action-oriented people, who, in every group, similarly assessed their progress in achieving goals. In particular, it was not confirmed that (as assumed in the hypothesis) the positive influence on the assessments of progress conducted by the action-oriented people in the case of the context motivating autonomously to implement an intention.

\section{DISCUSSION}

The aim of the research presented in this paper was to show the application of the Person-Environment Fit Theory of Lawrence A. Pervin (1968) for the analysis of the influence of individual predispositions and the situational context on the perseverance and effectiveness of the goal-directed action. The presented results have confirmed that the specific kind of fit between willpower differences and the means of motivational influence on the situational context is a significant perseverance and action effectiveness determinant.

The results of many studies conducted on the basis of the self-determination theory of Ryan and Deci $(2000,2006,2008)$ prove that the context evoking the sense of autonomy in comparison with the context creating the sense of control and pressure increases action perseverance and effectiveness and positively influences creativity, as well as satisfaction with obtained results.

The studies inspired by Kuhl's concept show, in turn, the significance of action control mechanisms for perseverance and the effectiveness of individual differences in the scope of the effectiveness. These studies confirm the better effects of action achieved by the action-oriented than by the state-oriented people (Baumann \& Kuhl, 2005; Beckmann \& Kellmann, 2004; Fuhrmann \& Kuhl, 1998; Kaschel \& Kuhl, 2004).

The self-determination theory draws attention to the positive influence of certain methods of motivating, emphasizing the need not so much to intensify motivation, as to change its character for a more autonomous one (Ryan \& Deci, 2000; Vansteenkiste \& Sheldon, 2006). In the scope of this theory, a lack of perseverance in action, low effectiveness, giving up an action before achieving a goal and results below individual capacities are consequence of the lack of identification with a goal, acting under pressure and coercion, which make it impossible to include a goal into their own self. The positive involvement and an autonomous context conducive to the identification and integration of a goal with the self positively influence effectiveness and action perseverance (Ryan \& Deci, 2008).

Kuhl's concept of willpower connects the ability to act perseveringly and effectively with action effectiveness control mechanisms (Kuhl, 1996; Kuhl et al. 2006). The high effectiveness in this scope, which characterizes action-oriented people, makes it possible for them not only to smoothly progress from deliberation to implementation, but, due to better insight into their own needs and preferences, to act in accordance with these preferences while facing difficulties, failures and obstacles (Baumann et al. 2005). Thereby, willpower is of particular significance not only for initiating the action itself, but also for persevering with it (Koole \& Kuhl, 2007; Kuhl, 1996). Simultaneously, the research confirms that the smaller the action effectiveness control mechanisms, the greater the correlation of perseverance and action effectiveness of external factors (pressure and coercion), which makes one inclined to commence an activity (Baumann \& Kuhl, 2005; Fuhrman \& Kuhl, 1998).

The conclusions drawn from Ryan and Deci's self-determination theory (2000) and Kuhl's concept of willpower (Kuhl 1996; Kuhl et al., 2006) considered together give a basis for the assumption that the influence of the situational context, or the method of motivating (control versus autonomy) on the results in the scope of effectiveness and action perseverance depends on individual differences in action effectiveness control mechanisms.

The results obtained in study 1 show very clearly the interactional influence of the situational context (method of motivating: external control versus autonomy support) and differences in action effectiveness control mechanisms. In accordance with the results obtained earlier by Baumann and Kuhl (2005) and by Fuhrmann and Kuhl (1998), it was confirmed that the perseverance and action effectiveness of state-oriented people is significantly greater under conditions of pressure and external control. In the study, state-oriented people executed the task for a longer time and achieved a higher level of its execution in the groups in which a manual created a sense of external control and pressure. Simultaneously, contrary to the predictions of Ryan and Deci's self-determination theory $(2000,2008)$ in the conditions of autonomy support and positive involvement, the state-oriented respondents obtained significantly lower indicators of both perseverance and effectiveness. In accordance with the adopted hypothesis, the action-oriented people 
did not reveal differences in perseverance and action effectiveness depending on the method of motivating.

Gollwitzer and Kuhl assume that effectiveness and action perseverance are determined not only by the strength of motivation, but also by action effectiveness control mechanisms (Gollwitzer \& Oettingen, 2011; Kuhl, 2000, 2011). The function of these mechanisms consists both in starting the action and in the protection of an adopted intention against the interfering action of factors such as: competitive goals and obstacles and difficulties both of situational (e.g. various kinds of temptation) and personal character (e.g. tiredness). It may be concluded that the differences between Kuhl's and Gollwitzer's views concern the opinion about the origin or the location of these mechanisms. In Gollwitzer's view, they are not directly related to individual predispositions. What follows intention implementation, as defined by Gollwitzer, is 'the separation of self' from actions, and taking control over achieving a goal over by a situation. In accordance with this proposal, it is important to become aware of the significant role that is played in actions by planning. After formulating a precise plan of action, regardless of other personal predispositions, which are sometimes adverse from the point of view of a goal being achieved, success in achieving an intended result becomes significantly more likely. In turn, in accordance with Kuhl's concept, action effectiveness control mechanisms are individual predispositions. Action-oriented people are characterized by high effectiveness in the scope of action control. Internal self-regulatory mechanisms make it possible for them to intuitively implement an intention, and, as a result, ensure an effective action.

The presented results of study 2 confirm the significance of the situational and personality action control mechanisms for progress in achieving goals. A manual persuading the reader to implement an intention exerts a positive influence on the progress assessment conducted by people, who are characterized by the personality-conditioned weakness of action control mechanisms. The presented results show that intention implementation somehow eliminates the adverse influence of the personality-conditioned low action effectiveness control mechanisms. Differences between state-oriented and action-oriented people in subjective progress assessment in achieving goals were revealed, first and foremost, in the group in which the respondents did not implement an intention. This research confirmed that the beneficial influence of intention implementation on the assessment conducted by the state-oriented people concerning progress in achieving goals occurs in a situation when, simultaneously, these people are motivated to implement an intention in a way that creates a sense of pressure/external control. This result, similarly to the one obtained in study 1 , matches the results of studies confirming higher action effec- tiveness level in the case of state-oriented people under conditions of external control (Baumann \& Kuhl, 2005; Fuhrmann \& Kuhl, 1998; cf. also KadzikowskaWrzosek, 2011a).

The results of study 2 failed to confirm any positive influence of intention implementation on people who are characterized by high action effectiveness control mechanism levels, i.e. action-oriented people. This result matches the results of the research of Webb et al. concerning intention implementation influence on action effectiveness in the case of people with varied conscientiousness levels. Intention implementation exerted a positive influence on action effectiveness in the case of low and moderate conscientiousness, while, simultaneously, it did not exert any influence in the case of people with high conscientiousness (Webb, Christian \& Armitage, 2007). Conscientiousness, as a quality in the Big Five model, described individual differences related to willpower. Therefore, it can be concluded that high conscientiousness levels, similarly to action-orientation, are related to high action control mechanism effectiveness levels (McCrae \& Costa, 1995). According to Kuhl, effective functioning of action control mechanisms in the case of action-oriented people is related to the involvement of intuitive processes (Baumann \& Kuhl, 2002; Koole \& Kuhl, 2007; Koole, McCullough, Kuhl \& Roelofsma, 2010). The increase in progress in achieving goals in the case of state-oriented people after intention implementation to the level of progress recorded in the case of action-oriented people can be regarded as evidence that both the conscious and unconscious (intuitive) action control mechanisms exert a similar influence on action (Bargh et al., 2001; Bargh, Gollwitzer \& Oettingen, 2010; cf. also: Kadzikowska-Wrzosek, 2011a).

Summing up the results of the two presented studies, it should be emphasized that they draw attention to the important fact that both perseverance and action effectiveness do not depend only on certain methods of motivating, or of willpower differences, or action effectiveness control mechanisms. Also of major significance is interaction or the specific fit of situational and personal factors. From that fact it should be concluded that the ways of influencing that are varied and take into consideration individual predispositions, able to positively influence both perseverance and action effectiveness, are necessary. Simultaneously, becoming familiar with the details of the specific character of these individual predispositions and the methods of motivating, it is possible to foresee additional consequences (apart from changes to perseverance and effectiveness), which should definitely also be taken into consideration. Although it is true that pressure improves effectiveness and action perseverance in the case of state-oriented people, it also has exceptionally negative consequences for other aspects of their functioning (Baumann \& Kuhl, 2005; Koole, Kuhl, Jostmann \& Vohs, 2005). 
Undoubtedly, further research, which would make it possible to analyse the results given in this paper and, perhaps, would suggest solutions beneficial for persevering and effective action, whilst being free of negative consequences caused by exerting pressure, is necessary.

\section{LIMITATIONS AND FUTURE DIRECTIONS}

There are limitations to the presented study (study 2) that should be acknowledged. First, in the course of discussing the research results and summing them up, it was emphasized that the analysis included intention implementation influence on subjective progress assessment. To state it precisely, however, what was analysed was the influence of the manual encouraging the implementation of an intention. Subjective progress assessment in the case of people who implemented an intention in accordance with the provided manual and the assessment that was declared by people who were not provided with such a manual, were compared. Simultaneously, it is impossible to exclude the possibility that it is also the researched individuals who were not provided with the manual that somehow spontaneously implemented intention, meaning that they developed a plan of achieving chosen goals. The results of research conducted by Gollwitzer et al. among others confirm that intention implementation is often used as a way of increasing action effectiveness (Gollwitzer \& Brandstätter, 1997). Therefore, it is a good idea to subject the researched individuals' tendency to spontaneously implement an intention to control during future research.

Second, the method of the measurement of progress in achieving individual goals, invoking solely researched individuals' declarations. On the one hand, this is a measure being commonly adopted by the researchers of goals, who during their studies take advantage of, first and foremost, the method of 'self-reports'; on the other hand, according to Koestner et al., subjective progress assessment is a progress indicator as good as goal criteria (Koestner et al., 2006). Apart from that, it seems to be justified in the case of so-called 'individual goals' to base them on subjective assessments. Nevertheless, the results obtained by means of this type of research certainly do not make it possible to give an exhaustive answer to the question of the influence of situational and personal factors and their interaction, on the action results achieved by an individual.

\section{REFERENCES}

Bargh, J.A., Gollwitzer, P.M., Lee-Chai, A., Barndollar, K. \& Trötschel, R. (2001). The automated will: Nonconscious activation and pursuit of behavior- al goals. Journal of Personality and Social Psycho$\log y, 81,1014-1027$.

Bargh, J.A., Gollwitzer, P.M. \& Oettingen, G. (2010). Motivation. In: S. Fiske, D. Gilbert \& G. Lindzey (eds.). Handbook of social psychology (pp. 268316). New York: Wiley.

Baumann, N., Kaschel, R. \& Kuhl, J. (2005). Striving for unwanted goals: Stress-depend discrepancies between explicit and implicit achievement motives reduce subjective well-being and increase psychosomatic symptoms. Journal of Personality and Social Psychology, 59, 781-799.

Baumann, N. \& Kuhl, J. (2002). Intuition, affect, and personality: Unconscious coherence judgments and self-regulation of negative affect. Journal of Personality and Social Psychology, 83, 1213-1223.

Baumann, N. \& Kuhl, J. (2005). How to resist temptation: The effects of external control versus autonomy. Journal of Personality, 73, 444-472.

Beckmann, J. \& Kellmann, M. (2004). Self-regulation and recovery: Approaching an understanding of the process of recovery from stress. Psychological Reports, 95, 1135-1153.

Carver, C.S. \& Scheier, M.F. (2011). Self-regulation of action and affect. In: K.D. Vohs \& R.F. Baumeister (eds.). Handbook of self-regulation: Research, theory, and applications. $2^{\text {nd }}$ ed. (pp. 3-21). New York, NY: Guilford.

Cervone, D., Mor, N., Orom, H., Scott, W. \& Shadel, W. (2004). Self-efficacy beliefs and the architecture of personality On knowledge, appraisal, and self-regulation. In: R.F. Baumeister \& K.D. Vohs (eds.). Handbook of self-regulation Research, theory, and applications (pp. 188-210). New York, NY: Guilford Press.

Cervone, D., Mor, N., Orom, H., Shadel, W.G., Scott, W.D. (2011). Self-efficacy beliefs on the architecture of personality: On knowledge, appraisal, and self-regulation. In: K. Vohs \& R.F. Baumeister (eds.). Handbook of self-regulation: Research, theory, and applications (pp. 188-210). $2^{\text {nd }}$ ed. New York: Guilford.

Fuhrmann, A. \& Kuhl, J. (1998). Maintaining a healthy diet: Effects of personality and self-reward versus self-punishment on commitment to and enactment of self-chosen and assigned goals. Psychology and Health, 13, 651-686.

Gollwitzer, P.M. \& Brandstätter, V. (1997). Implementation intentions and effective goal pursuit. Journal of Personality and Social Psychology, 73, 186-199.

Gollwitzer, P.M., Fujita, K. \& Oettingen, G. (2004). Planning and the implementation of goals. In: R.F. Baumeister \& K.D. Vohs (eds.). Handbook of self-regulation. Research, theory, and applications (pp. 211-228). New York: The Guilford Press.

Gollwitzer, P.M. \& Oettingen, G. (2011). Planning promotes goal striving. In: K.D. Vohs \& R.F. Baumeister (eds.). Handbook of self-regulation: Research, 
theory, and applications (pp. 162-185). $2^{\text {nd }}$ ed. New York: Guilford.

Kadzikowska-Wrzosek, R. (2010). Wolna wola w świetle badań współczesnej psychologii nad procesami samoregulacji oraz samokontroli. Psychologia Spoteczna, 5, 330-344.

Kadzikowska-Wrzosek, R. (2011a). Subiektywna ocena postępu w realizacji celu: Wpływ implementacji intencji i różnic indywidualnych w sposobie formułowania celów oraz sile woli. Psychologia Spoteczna, 6, 49-66.

Kadzikowska-Wrzosek, R. (2011b). Wytrwałość i skuteczność działania: Wpływ kontekstu sytuacyjnego oraz siły woli. Roczniki Psychologiczne, 14, 159-186.

Kadzikowska-Wrzosek, R. (2012). Typ regulacji działania w wytrwałość i skuteczność działania: Wpływ siły woli i kontekstu sytuacyjnego. Studia Psychologiczne, 50, 31-47.

Kaschel, R. \& Kuhl, J. (2004). Motivational counseling in an extended functional context: Personality systems interaction theory and assessment. In: W.M. Cox \& E. Klinger (eds.). Motivational counseling: Motivating people for change (pp. 99-119). Sussex: Wiley.

Kazén, M., Baumann, N. \& Kuhl, J. (2003). Self-infiltration vs. self-compatibility checking in dealing with unattractive tasks: The moderating influence of state vs. action orientation. Motivation and emotion, 27, 157-197.

Koestner, R., Horberg, E.J., Gaudreau, P., Powers, T., Di Dio, P., Bryan, Ch., Jochum, R. \& Salter, N. (2006). Bolstering implementation plans for the long haul: The benefits of simultaneously boosting self-concordance or self-efficacy. Personality and social Psychology Bulletin, 11, 1547-1558.

Koole, S.L. (2009). The psychology of emotion regulation: An integrative review. Cognition and Emotion, 23, 4-41.

Koole, S.L. \& Kuhl, J. (2007). Dealing with unwanted feelings: The role of affect regulation in volitional action control. In: J. Shah \& W. Gardner (eds.). Handbook of motivation science (pp. 295-307). New York: Guilford.

Koole, S.L., Kuhl, J., Jostmann, N.B. \& Vohs, K.D. (2005). On the hidden benefits of state orientation: Can people prosper without efficient affect regulation skills? In: A. Tesser, J. Wood \& D.A. Stapel (eds.). On building, defending, and regulating the self: A psychological perspective (pp. 217-243). London: Taylor and Francis.

Koole, S.L., McCullough, M.L., Kuhl, J. \& Roelofsma, P.H.M.P. (2010). Why religion's burdens are light: From religiosity to implicit self-regulation. Personality and Social Psychology Review, 14, 95-107.

Kuhl, J. (1996). Who controls whom "when I control myself"? Psychological Inquiry, 7, 61-68.

Kuhl, J. (2000). A functional-design approach to motivation and self-regulation: The dynamics of per- sonality systems interactions. In: Boekaerts, M., Pintrich, P.R. \& Zeidner, M. (eds.). Handbook of self-regulation (pp. 111-169). San Diego: Academic Press.

Kuhl, J. (2011). Adaptive and maladaptive pathways of self-development: Mental health and interactions among personality systems. Psychologia Rozwojowa, 16, 9-31.

Kuhl, J. \& Kazén, M. (1994). Self-discrimination and memory: State orientation and false self-ascription of assigned activities. Journal of Personality and Social Psychology, 66, 1103-1115.

Kuhl, J. \& Kazén, M. (1999). Volitional facilitation of difficult intentions: Joint activation of intention memory and positive affect removes Stroop interference. Journal of Experimental Psychology: General, 128, 382-399.

Kuhl, J., Kazén, M. \& Koole, S.L. (2006). Putting self-regulation theory into practice: A user's manual. Applied Psychology: An international Review, 55, 408-418.

Little, B.R. (1993). Personal Projects and the distributed self: Aspects of a conative psychology. In: J. Suls (ed.). Psychological perspectives in the self and social perspective. Vol. 4. New Jersey: Lawrance Erlbaum Associates, Publishers.

Little, B.R., Lecci, L. \& Watkinson, B. (1992). Personality and personal projects: Linking Big Five and PAC units of analysis. Journal of Personality, 60, 501-525.

Łukaszewski, W. \& Marszał-Wiśniewska, M. (2006). Wytrwatość w działaniu. Wyznaczniki sytuacyjne i osobowościowe [Perseverance in action. Situational and personality determinants]. Gdańsk: Wydawnictwo GWP.

Markus, H. \& Ruvalo, A. (1989). Possible selves: Personalized representations of goals. In: L.A. Pervin (ed.). Goal concepts in personality and social psychology (pp. 211-241). New Jersey: Lawrence Erlbaum Associates, Publishers.

Marszał-Wiśniewska, M. (2002). Adaptacja Skali Kontroli Działania J. Kuhla (ACS-90). Studia Psychologiczne, 40, 77-102.

Mądrzycki, T. (1996). Osobowość jako system tworzący i realizujący plany życiowe [Personality as a system creating and implementing life plans]. Gdańsk: Wydawnictwo GWP.

McCrae, R.R. \& Costa P.T., Jr. (1995). Trait explanations in personality psychology. European Journal of Personality, 9, 231-252.

Parker, S.L., Jimmieson, N.L. \& Amiot, C.E. (2013). Self-determination, control, and reactions to changes in workload: A work simulation. Journal of Occupational Health Psychology, 18, 173-190.

Pervin, L.A. (1968). Performance and satisfaction as a function of individual-environment fit. Psychological Bulletin, 69, 56-68. 
Polivy, J. \& Herman, C.P. (2000). The False Hope Syndrome: Unfulfilled expectations of self-change. Current Directions in Psychological Science, 9, 128-131.

Prochaska, J.O., DiClemente, C.C. \& Norcross, J.C. (1992). In search of how people change: Applications to addictive behavior. American Psychologist, 47, 1102-1114.

Rothman, A.J. (2000). Toward a theory-based analysis of behavioral maintenance. Health Psychology, 19, 64-69.

Rothman, A.J., Baldwin, A. \& Hertel, A. (2004). Selfregulation and behavior change: Disentangling behavioral initiation and behavioral maintenance. In: R.F. Baumeister \& K.D. Vohs (eds.). The handbook of self-regulation (pp. 130-150). New York: Guilford.

Ryan, R.M. \& Deci, E.L. (2000). Self-determination theory and the facilitation of intrinsic motivation, social development, and well-being. American Psychologist, 55, 68-78.

Ryan, R.M. \& Deci, E.L. (2006). Self-regulation and the problem of human autonomy: Does psychology need choice, self-determination and will? Journal of Personality, 74, 1557-1585.

Ryan, R.M. \& Deci, E.L. (2008). From Ego Depletion to Vitality: Theory and Findings Concerning the Facilitation of Energy Available to the Self. Social and Personality Psychology, 2, 702-717.

Sansone, C. \& Harackiewicz, J.M. (1996). "I don't feel like it" The function of interest in self-regulation. In: L.L. Martin \& A. Tesser (eds.). Interactions among goals, affect, and self-regulation (pp. 175-202). New Jersey: Lawrence Erlbaum.

Sansone, C., Wiebe, D.J. \& Morgan, C. (1999). SelfRegulating Interest: The Moderating Role of Hardiness and Conscientiousness. Journal of Personality, 4, 701-735.

Vansteenkiste, M. \& Sheldon, K.M. (2006). There's nothing more practical than a good theory: Integrating motivational interviewing and self-determination theory. British Journal of Clinical Psychology, 45, 63-82.

Vohs, K.D. \& Schmeichel, B.J. (2007). Self-Regulation: How and Why People Reach (and Fail to Reach) Their Goals. In: C. Sedikides \& S. Spencer (eds.). Frontiers in Social Psychology: The Self (pp. 139162). Philadelphia, PA: Psychology Press.

Webb, T.L., Christian, J. \& Armitage, C.J. (2007). Helping students turn up for class: Does personality moderate the effectiveness of an implementation intention intervention? Learning and Individual Differences, 17, 316-327.

Wieber, F. \& Gollwitzer, P.M. (2010). Overcoming procrastination through planning. In: C. Andreou \& M.D. White (eds.). The thief of time: Philosophical essays on procrastination (pp. 185-205). New York: Oxford University Press. 